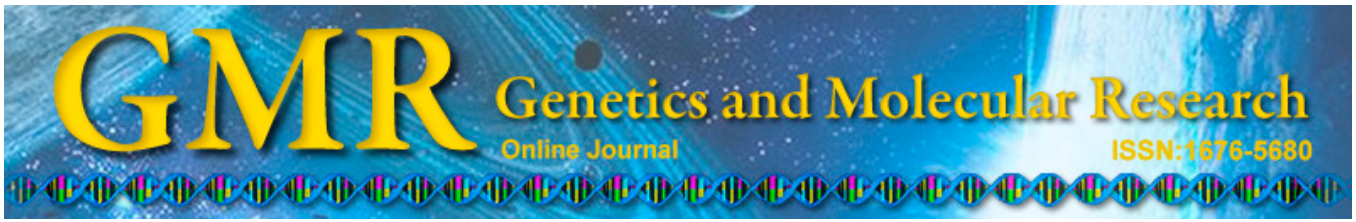

\title{
Association of GSTP1 and XRCC1 gene polymorphisms with clinical outcomes of patients with advanced non-small cell lung cancer
}

\author{
J.Y. Liu ${ }^{1,2}$, Q.M. Liu ${ }^{3}$ and L.R. Li ${ }^{2}$ \\ ${ }^{1}$ Department of Respiration, Shandong Provincial Hospital, \\ Shandong University, Ji'nan, China \\ ${ }^{2}$ Department of Emergency, People's Hospital of Linyi, Linyi, China \\ ${ }^{3}$ Department of Intensive Care Medicine, People's Hospital of Linyi, Linyi, China \\ Corresponding author: L.R. Li \\ E-mail: lilanrong51@163.com \\ Genet. Mol. Res. 14 (3): 10331-10337 (2015) \\ Received January 19, 2015 \\ Accepted May 29, 2015 \\ Published August 28, 2015 \\ DOI http://dx.doi.org/10.4238/2015.August.28.19
}

\begin{abstract}
We investigated the association between the polymorphisms GSTP1 rs1695 and XRCC1 rs1799782 and rs25487 and the clinical outcome of patients with non-small cell lung cancer (NSCLC) receiving cisplatin-based chemotherapy. Genotyping of GSTP1 rs1695 and XRCC1 rs1799782, and rs25487 was conducted by polymerase chain reaction-restriction fragment length polymorphism analysis. By conditional logistic regression analysis, patients carrying the GG genotype of GSTP1 rs1695 and the AA genotype of XRCC1 rs 25487 were found to be more highly associated with response to chemotherapy than were those carrying the AA genotype; the ORs (95\%CIs) were $0.13(0.04-0.37)$ and 3.37 (1.44-8.53), respectively. Presence of the GG genotype of GSTP1 rs1695 and the GA and AA genotypes of $X R C C 1$ rs25487 was associated with overall survival of
\end{abstract}


NSCLC, and the hazards ratios $(95 \% \mathrm{CI})$ were 4.35 (1.40-17.92), 0.53 (0.31-0.91), and 0.39 (0.18-0.83), respectively. The results of our study suggest that the GSTP1 rs1695 and XRCC1 rs25487 polymorphisms might affect the clinical outcome of patients with advanced NSCLC receiving cisplatin-based chemotherapy.

Key words: GSTP 1; XRCC1; Polymorphism; Clinical outcome; Advanced non-small cell lung cancer

\section{INTRODUCTION}

Lung cancer has been one of the most common cancers worldwide for several decades, and it is the main cause of cancer-related mortality (IARC, 2012). There are estimated to have been 1.8 million new cases in 2012 (12.9\% of the total), $58 \%$ of which occurred in less developed regions (IARC, 2012). Approximately $80 \%$ of patients with lung cancer have nonsmall cell lung cancer (NSCLC), and most patients with NSCLC are already in an advanced stage when they are diagnosed.

Despite the development of therapeutics for NSCLC and the improvement of diagnosis in recent years, patients with NSCLC realize only a 19-38\% 5-year survival rate after diagnosis (Goldstraw et al., 2007). Previous studies have reported that the outcome of patients was significantly improved after receiving cisplatin-based chemotherapy, and that the efficacy and toxicity of chemotherapy treatment are largely individualized. Additional studies have shown that genetic factors can play an important role in the different effects of cisplatin-based chemotherapy treatments (Alberts et al., 1991; Zhou et al., 2011). For example, gene polymorphisms involved in altering the activities of enzymes and transporters have been demonstrated to influence the efficacy of cisplatin-based chemotherapy (Evans and Relling, 1999).

Glutathione S-transferase P1 (GSTP1) is a member of the glutathione S-transferase class of proteins, and is widely expressed in different human tissues including lung and liver. It contributes to the phase II metabolism of xenobiotics, which is involved in the key process of cisplatin biotransformation (Boyer, 1989). X-ray repair cross-complementing group 1 (XRCC1) is a fundamental member of the base excision repair pathway, and plays a prominent role in both single-strand break repair and in base excision repair (Lindahl and Wood, 1999). The XRCC1 protein interacts with ligase III and poly(ADP-ribose) polymerase to efficiently repair DNA damage including cisplatin-induced damage (Zhu and Lippard, 2009).

In this study, we investigated the association between the GSTP1 rs1695 and XRCC1 rs1799782 and rs25487 polymorphisms and the clinical outcome of patients with NSCLC who had received cisplatin-based chemotherapy.

\section{MATERIAL AND METHODS}

\section{Subjects}

A prospective study was conducted on 322 patients with NSCLC, consecutively selected from the People's Hospital of Linyi between January 2009 to December 2011. All hospital patients with newly diagnosed primary NSCLC were asked to participate in the study 
within 1 month after diagnosis, and all cancers were histopathologically confirmed. Patients who had a history of other malignant cancer within the past 5 years, who were pregnant or lactating, or who had cardiopulmonary insufficiency, serious cardiovascular disease, or serious infection as well as severe malnutrition were excluded from our study. The protocol of our study was approved by the Ethics Committee of the People's Hospital of Linyi.

\section{Chemotherapy treatment}

All subjects received one of the following cisplatin-based combination chemotherapy regimens: cisplatin and gemcitabine, cisplatin and vinorelbine, cisplatin and paclitaxel, or cisplatin and docetaxel. The chemotherapy was repeated every 3 weeks, and the treatment was continued for a maximum of four cycles. The treatments were suspended upon disease progression or unacceptable toxicity was noted.

The patients were followed up every month by telephone up to their death or until the end of the study. The response to chemotherapy was classified by response evaluation criteria in solid tumors (Duffaud and Therasse, 2000). Overall survival (OS) was defined as the time from the beginning of treatment to death. Patients without death by the time of the analysis were terminated at the date of the last follow-up.

\section{Blood samples and genotyping}

Each patient was asked to provide $5 \mathrm{~mL}$ peripheral blood, which was stored at $-70^{\circ} \mathrm{C}$ until use. Genomic DNA was isolated from the peripheral blood using the TIANamp Blood DNA Kit (Tiangen, Beijing, China) according to the manufacturer instructions. Genotyping of the GSTP1 rs1695 and XRCC1 rs1799782 and rs25487 polymorphisms was conducted by polymerase chain reaction (PCR)-restriction fragment length polymorphism assay. Primers for GSTP1 rs1695 and XRCC1 rs1799782 and rs25487 amplification were designed using the Sequenom Assay Design 3.1 software (San Diego, CA, USA). The PCR was performed in 50$\mu \mathrm{L}$ reaction solution containing $25 \mathrm{mM} \mathrm{MgCl}, 2 \mathrm{mM} 4 \mathrm{X}$ dNTPs, $20 \mu \mathrm{M}$ of each primer, and $5 \mathrm{U} / \mu \mathrm{L}$ Taq DNA polymerase. The PCR was performed using the following conditions: one cycle at $94^{\circ} \mathrm{C}$ for $5 \mathrm{~min}$, followed by 35 cycles of denaturation at $94^{\circ} \mathrm{C}$ for $45 \mathrm{~s}$, annealing at $62^{\circ} \mathrm{C}$ for $60 \mathrm{~s}$, and extension at $72^{\circ} \mathrm{C}$ for $60 \mathrm{~s}$, with a final extension at $72^{\circ} \mathrm{C}$ for $10 \mathrm{~min}$. The PCR products were visualized by $1.0 \%$ agarose gel electrophoresis and stained using ethidium bromide followed by examination with UV light. We randomly selected $5 \%$ of the included patients for repeated genotyping, and the results showed $100 \%$ concordance.

\section{Statistical analysis}

Continuous variables are reported as means \pm standard deviation, and categorical variables are reported as N (\%) of study participants. Patients who showed complete or partial response were defined as "responders" and those with stable or progressive disease were regarded as "non-responders". ORs and their corresponding 95\%CIs were used to assess the associations between gene polymorphisms of GSTP1 and XRCC1 and response to chemotherapy in patients with NSCLC. The associations between the GSTP1 and XRCC1 gene polymorphisms and the OS of patients with NSCLC were assessed by a Cox proportional 
hazard model, and the results are reported by hazard ratios (HRs) and their 95\%CIs. Survival distributions were estimated using the Kaplan-Meier method and assessed using the log-rank test. A P value of less than 0.05 was considered to be statistically significant. All statistical analyses were performed using the SPSS 16.0 software (SPSS Inc., Chicago, IL, USA).

\section{RESULTS}

The demographic and clinical characteristics of all patients with NSCLC are shown in Table 1. The mean age of the subjects with NSCLC was $62.5 \pm 9.5$ years old (ranging from 37 to 81 years). Of the 322 patients, $226(70.19 \%)$ were men, $140(43.48 \%)$ had a habit of smoking tobacco, $154(47.83 \%)$ had a habit of drinking alcohol, $234(72.67 \%)$ were at tumor, lymph node, metastasis (TNM) stage IV, and 181 (56.21\%) exhibited adenocarcinoma.

\begin{tabular}{|c|c|c|}
\hline Characteristics & Number of patients & $\%$ \\
\hline \multicolumn{3}{|l|}{ Age (years) } \\
\hline$<60$ & 139 & 43.17 \\
\hline$\geq 60$ & 183 & 56.83 \\
\hline \multicolumn{3}{|l|}{ Gender } \\
\hline Male & 226 & 70.19 \\
\hline Female & 96 & 29.81 \\
\hline \multicolumn{3}{|l|}{ Tobacco smoking } \\
\hline Never & 182 & 56.52 \\
\hline Ever & 140 & 43.48 \\
\hline \multicolumn{3}{|l|}{ Alcohol drinking } \\
\hline Never & 168 & 52.17 \\
\hline Ever & 154 & 47.83 \\
\hline \multicolumn{3}{|l|}{ TNM stage } \\
\hline IIIB & 88 & 27.33 \\
\hline IV & 234 & 72.67 \\
\hline \multicolumn{3}{|l|}{ Histology } \\
\hline Adenocarcinoma & 181 & 56.21 \\
\hline Squamous carcinoma & 120 & 37.27 \\
\hline Other & 21 & 6.52 \\
\hline
\end{tabular}

$\mathrm{NSCLC}=$ non-small cell lung cancer; $\mathrm{TNM}=$ tumor, lymph node, metastasis

At the end of the follow-up, 198 patients with NSCLC showed good response to cisplatin-based chemotherapy, with a response rate of $61.49 \%$. By conditional logistic regression analysis, patients carrying the GG genotype of GSTP1 rs1695 showed a significantly poorer response to chemotherapy than did those carrying the AA genotype; the OR $(95 \% \mathrm{CI})$ was 0.13 (0.04-0.37) (Table 2). Furthermore, the AA genotype of XRCC1 rs25487 was associated with a better response to chemotherapy compared with that of the GG genotype; the OR $(95 \% \mathrm{CI})$ was 3.37 (1.44-8.53). However, we did not find significant association between XRCC1 rs1799782 polymorphism and the response to chemotherapy in patients with NSCLC.

At the end of December 2014, 209 patients had died from all causes, and the 5-year survival rate was $36.96 \%$. In the Cox proportional hazard model, the GG genotype of GSTP1 rs 1695 was associated with increased risk of death from NSCLC, and the HR $(95 \% \mathrm{CI})$ was 4.35 (1.40-17.92) (Table 3). Furthermore, the GA and AA genotypes of XRCC1 rs25487 significantly decreased the risk of death from NSCLC, and the HRs (95\%CIs) were $0.53(0.31$ $0.91)$ and $0.39(0.18-0.83)$, respectively. 
Table 2. Association between GSTP1 and XRCC1 gene polymorphisms and patient response to cisplatin-based chemotherapy.

\begin{tabular}{|c|c|c|c|c|c|c|c|c|}
\hline Genotypes & Total number & $\%$ & Responders & $\%$ & Non-responders & $\%$ & OR $(95 \% \mathrm{CI})^{1}$ & $P$ value \\
\hline \multicolumn{9}{|c|}{ GSTP1 rs1695 } \\
\hline AA & 181 & 56.2 & 123 & 62.12 & 58 & 46.77 & 1.0 (Ref.) & - \\
\hline $\mathrm{AG}$ & 114 & 35.5 & 69 & 34.85 & 45 & 36.29 & $0.72(0.43-1.22)$ & 0.19 \\
\hline GG & 27 & 8.3 & 6 & 3.03 & 21 & 16.94 & $0.13(0.04-0.37)$ & $<0.05$ \\
\hline \multicolumn{9}{|c|}{$X R C C 1$ rs 1799782} \\
\hline $\mathrm{CC}$ & 204 & 63.4 & 119 & 60.10 & 85 & 68.55 & 1.0 (Ref.) & - \\
\hline CT & 84 & 26.1 & 54 & 27.27 & 30 & 24.19 & $1.29(0.74-2.26)$ & 0.35 \\
\hline TT & 34 & 10.5 & 25 & 12.63 & 9 & 7.26 & $1.98(0.84-5.07)$ & 0.09 \\
\hline \multicolumn{9}{|c|}{$X R C C 1 \mathrm{rs} 25487$} \\
\hline GG & 140 & 43.5 & 75 & 37.88 & 65 & 52.42 & 1.0 (Ref.) & - \\
\hline GA & 138 & 42.7 & 88 & 44.44 & 50 & 40.32 & $1.53(0.92-2.54)$ & 0.08 \\
\hline AA & 44 & 13.8 & 35 & 17.68 & 9 & 7.26 & $3.37(1.44-8.53)$ & 0.002 \\
\hline
\end{tabular}

${ }^{1}$ Adjusted for gender, age, tobacco smoking, alcohol drinking, TNM stage, and histology. TNM = tumor, lymph node, metastasis.

Table 3. Cox regression analysis of the association between GSTP1 and XRCC1 gene polymorphisms and overall survival of NSCLC.

\begin{tabular}{|c|c|c|c|c|c|c|}
\hline Genotypes & Deaths & $\%$ & Survivors & $\%$ & HR $(95 \% \mathrm{CI})^{1}$ & P value \\
\hline \multicolumn{7}{|c|}{ GSTP1 rs1695 } \\
\hline AA & 103 & 50.74 & 78 & 65.55 & 1.0 (Ref.) & - \\
\hline $\mathrm{AG}$ & 77 & 37.93 & 37 & 31.09 & $1.58(0.94-2.66)$ & 0.07 \\
\hline GG & 23 & 11.33 & 4 & 3.36 & $4.35(1.40-17.92)$ & 0.005 \\
\hline \multicolumn{7}{|c|}{ XRCC1 rs 1799782} \\
\hline $\mathrm{CC}$ & 134 & 66.01 & 70 & 58.82 & 1.0 (Ref.) & - \\
\hline $\mathrm{CT}$ & 50 & 24.63 & 34 & 28.57 & $0.77(0.44-1.34)$ & 0.32 \\
\hline TT & 19 & 9.36 & 15 & 12.61 & $0.66(0.30-1.49)$ & 0.27 \\
\hline \multicolumn{7}{|c|}{$X R C C 1$ rs 25487} \\
\hline GG & 101 & 49.75 & 39 & 32.77 & 1.0 (Ref.) & - \\
\hline GA & 80 & 39.41 & 58 & 48.74 & $0.53(0.31-0.91)$ & 0.01 \\
\hline $\mathrm{AA}$ & 22 & 10.84 & 22 & 18.49 & $0.39(0.18-0.83)$ & 0.006 \\
\hline
\end{tabular}

${ }^{1}$ Adjusted for gender, age, tobacco smoking, alcohol drinking, TNM stage, and histology. NSCLC $=$ non-small cell lung cancer; $\mathrm{HR}=$ hazard ratio; $\mathrm{TNM}=$ tumor, lymph node, metastasis.

\section{DISCUSSION}

In the present study, we investigated the influence of polymorphisms of GSTP1 and $X R C C 1$ on treatment response and OS in patients with NSCLC treated with cisplatin-based chemotherapy. Our study found that patients carrying the GG genotype of GSTP1 rs1695 and the AA genotype of $X R C C 1$ rs 25487 were associated with a positive response to chemotherapy, and that the GG genotype of GSTP1 rs1695 and the GA and AA genotypes of XRCC1 rs25487 were associated with the OS of NSCLC. Therefore, these results suggested that the GSTP1 rs1695 and XRCC1 rs25487 polymorphisms could influence the clinical outcomes of patients with NSCLC.

GSTP1 is a phase II detoxification enzyme, which is involved in the detoxification of cisplatin (Sheehan et al., 2001). A previous study has reported that overexpression of GSTP1 in patients with NSCLC decreased their sensitivity to platinum agents in vitro (Oguri et al., 2000). The GSTP1 rs1695 polymorphism changes the thermal stability and conjugation capacity of GSTP1, which alters the ability of GSTP1 to detoxify chemotherapeutic agents and modulates drug responses. Several previous studies have reported associations between GSTP1 rs1695 
polymorphisms and responses to cisplatin-based chemotherapy in esophageal cancer, head and neck squamous cell carcinoma, and ovarian cancer (Cabelguenne et al., 2001; Khrunin et al., 2010; Wang et al., 2011). Cabelguenne et al. (2001) found that the GSTP1 polymorphism was associated with response to cisplatin-based chemotherapy in larynx cancer. Khrunin et al. (2010) found that the GSTP1 rs1695 polymorphism was strongly associated with progressionfree survival of ovarian cancer in patients receiving cisplatin-based chemotherapy. Regarding the association between the GSTP1 rs1695 polymorphism and the clinical outcome of patients with NSCLC, several previous studies have reported that the GSTP1 rs1695 polymorphism might be a predictive marker for the treatment response of patients with advanced NSCLC (Booton et al., 2006; Sun et al., 2010; Ke et al., 2012). However, one study did not find that GSTP1 variation could affect the response to chemotherapy regimens containing cisplatin (Unsal et al., 2003). The discrepancies between these results might be a consequence of differences in ethnicities, study design, and sample size.

XRCC1 serves as a scaffold factor in base excision repair, for which functional polymorphisms have been identified. The $X R C C 1$ rs25487 polymorphism can change the activity of the XRCC1 protein and thus influence the DNA repair capacity (Au et al., 2003). Four previous studies have reported an association between XRCC1 rs25487 polymorphism and the response to cisplatin-based chemotherapy (de las Peñas et al., 2006; Hong et al., 2009; Li et al., 2011; Liu et al., 2011). Hong et al. (2009) and Liu et al. (2011) found that XRCC1 rs25487 polymorphism could predict the sensitivity of NSCLC to cisplatin-based chemotherapy. However, Li et al. (2011) and de las Peñas et al. (2006) found no statistically significant association between the XRCC1 rs25487 polymorphism and the response to chemotherapy in patients with NSCLC.

Our study suggests that GSTP1 rs1695 and XRCC1 rs25487 might affect the clinical outcome of patients with advanced NSCLC receiving cisplatin-based chemotherapy. This observation could be used in personalized chemotherapy strategies to increase the response rate and prolonged survival time, and also provides incentive to explore the predictive value of other genes.

\section{Conflicts of interest}

The authors declare no conflict of interest.

\section{REFERENCES}

Alberts DS, Garcia D and Mason-Liddil N (1991). Cisplatin in advanced cancer of the cervix: an update. Semin. Oncol. 18: 11-24.

$\mathrm{Au}$ WW, Salama SA and Sierra-Torres CH (2003). Functional characterization of polymorphisms in DNA repair genes using cytogenetic challenge assays. Environ. Health Perspect. 111: 1843-1850.

Booton R, Ward T, Heighway J, Ashcroft L, et al. (2006). Glutathione-S-transferase P1 isoenzyme polymorphisms, platinum-based chemotherapy, and non-small cell lung cancer. J. Thorac. Oncol. 1: 679-683.

Boyer TD (1989). The glutathione S-transferases: an update. Hepatology 9: 486-496.

Cabelguenne A, Loriot MA, Stucker I, Blons H, et al. (2001). Glutathione-associated enzymes in head and neck squamous cell carcinoma and response to cisplatin-based neoadjuvant chemotherapy. Int. J. Cancer 93: 725-730.

de las Peñas R, Sanchez-Ronco M, Alberola V, Taron M, et al. (2006). Polymorphisms in DNA repair genes modulate survival in cisplatin/gemcitabine-treated non-small-cell lung cancer patients. Ann. Oncol. 17: 668-675.

Duffaud F and Therasse P (2000). New guidelines to evaluate the response to treatment in solid tumors. Bull. Cancer 87: $881-886$. 
Evans WE and Relling MV (1999). Pharmacogenomics: translating functional genomics into rational therapeutics. Science 286: 487-491.

Goldstraw P, Crowley J, Chansky K, Giroux DJ, et al. (2007). The IASLC Lung Cancer Staging Project: proposals for the revision of the TNM stage groupings in the forthcoming (seventh) edition of the TNM Classification of malignant tumours. J. Thorac. Oncol. 2: 706-714.

Hong CY, Xu Q, Yue Z, Zhang Y, et al. (2009). Correlation of the sensitivity of NP chemotherapy in non-small lung cancer with DNA repair gene XRCC1 polymorphism. Ai Zheng 28: 1291-1297.

International Agency for Research on Cancer (IARC), World Health Organization (2012). GLOBOCAN 2012: Estimated Incidence, Mortality and Prevalence Worldwide in 2012. Lung Cancer. Available at [http://globocan.iarc.fr/Pages/ fact_sheets_cancer.aspx]. Accessed January 1, 2014.

Ke HG, Li J, Shen Y, You QS, et al. (2012). Prognostic significance of GSTP1, XRCC1 and XRCC3 polymorphisms in non-small cell lung cancer patients. Asian Pac. J. Cancer Prev. 13: 4413-4416.

Khrunin AV, Moisseev A, Gorbunova V and Limborska S (2010). Genetic polymorphisms and the efficacy and toxicity of cisplatin-based chemotherapy in ovarian cancer patients. Pharmacogenomics $J$. 10: 54-61.

Li Y, Huang XE, Jin GF, Shen HB, et al. (2011). Lack of any relationship between chemotherapy toxicity in non-small cell lung cancer cases and polymorphisms in XRCC1 codon 399 or XPD codon 751. Asian Pac. J. Cancer Prev. 12: 739-742.

Lindahl T and Wood RD (1999). Quality control by DNA repair. Science 286: 1897-1905.

Liu L, Yuan P, Wu C, Zhang X, et al. (2011). Assessment of XPD Lys751Gln and XRCC1 T-77C polymorphisms in advanced non-small-cell lung cancer patients treated with platinum-based chemotherapy. Lung Cancer 73: 110-115.

Oguri T, Fujiwara Y, Katoh O, Daga H, et al. (2000). Glutathione S-transferase-pi gene expression and platinum drug exposure in human lung cancer. Cancer Lett. 156: 93-99.

Sheehan D, Meade G, Foley VM and Dowd CA (2001). Structure, function and evolution of glutathione transferases: implications for classification of non-mammalian members of an ancient enzyme superfamily. Biochem. J. 360: 1-16.

Sun N, Sun X, Chen B, Cheng H, et al. (2010). MRP2 and GSTP1 polymorphisms and chemotherapy response in advanced non-small cell lung cancer. Cancer Chemother. Pharmacol. 65: 437-446.

Unsal M, Akpolat I and Kandemir B (2003). Glutathione-S transferase-pi expression in non small cell lung cancer in the assessment of response to chemotherapy. Saudi Med. J. 24: 493-498.

Wang Y, Chen J, Li X, He Y, et al. (2011). Polymorphisms of ERCC1 and their effects on the efficacy of cisplatin-based chemotherapy in advanced esophageal carcinoma. Oncol. Rep. 25: 1047-1052.

Zhou F, Yu Z, Jiang T, Lv H, et al. (2011). Genetic polymorphisms of GSTP1 and XRCC1: prediction of clinical outcome of platinum-based chemotherapy in advanced non-small cell lung cancer (NSCLC) patients. Swiss Med. Wkly. 141: w13275.

Zhu G and Lippard SJ (2009). Photoaffinity labeling reveals nuclear proteins that uniquely recognize cisplatin-DNA interstrand cross-links. Biochemistry 48: 4916-4925. 